\title{
Use of Photocatalysis for Degradation of Glyphosate in Potable Water of CKDu Prevalent Areas
}

\author{
Jayasekara P.P., Gunarathna S., Gunawardana B.*, Jayaweera M., Manatunge J. and \\ Zoysa K.
}

\author{
${ }^{1}$ Department of Civil Engineering, University of Moratuwa, Sri Lanka \\ *buddhi75@yahoo.com
}

\begin{abstract}
Glyphosate, which is commercially available as Roundup®, was the most widely used herbicide in Sri Lanka until recently. Recent studies report the presence of glyphosate in different water sources (drinking water, surface water, groundwater) in the Chronic Kidney Disease of unknown etiology $(\mathrm{CKDu})$ prevalent areas containing elevated hardness levels. Additionally, WHO studies conducted in 2013, provide evidence of the presence of glyphosate in trace levels in urine samples of CKDu subjects. Thus, glyphosate is suspected to be one of the causal factors for $\mathrm{CKDu}$ and its removal, when present in potable water with high hardness levels, is a challenging engineering task. Photocatalysis is recognised to be one of the promising technologies for degradation of glyphosate. Hence, this study focuses on investigating the effectiveness and efficiency of the photocatalysis process for degradation of glyphosate from potable waters containing high hardness levels. Experiments were conducted with high purity Glyphosate and Roundup ${ }^{\circledR}$ in the absence $\left(0 \mathrm{mg} / \mathrm{l}\right.$ as $\left.\mathrm{CaCO}_{3}\right)$ and presence of hardness $\left(1,500 \mathrm{mg} / \mathrm{l}\right.$ as $\left.\mathrm{CaCO}_{3}\right)$. A sunlight activated water purifier bag available in the market that consists of a Titanium Dioxide membrane was used for application of the photocatalysis process. A $3.0 \mathrm{~L}$ water sample containing Glyphosate/Roundup ${ }^{\circledR}$ (glyphosate concentration $1 \mathrm{mg} / \mathrm{L}$ ) was continuously exposed to sunlight for six (06) hours. A solar irradiance meter was used to measure the sunlight intensity. Samples from the reaction solution were collected at predetermined time intervals and analysed for glyphosate and amninomethyphosphonic acid (AMPA) using GC/MS and LC/MS in the absence and presence of hardness, respectively. A rapid decrease in glyphosate concentration to levels below $0.7 \mathrm{mg} / \mathrm{l}$ (USEPA Maximum Contaminant Level) was observed during the first 60 minutes of reaction time under all experimental conditions studied. The concentration of AMPA detected was below the level of quantification in all experiments implying that complete degradation of Glyphosate has occurred until inorganic phosphate is produced. When using high purity glyphosate or Roundup ${ }^{\circledR}$, slower degradation rates were observed in the presence of hardness compared to that in the absence of hardness. Retardation of glyphosate degradation in the presence of hardness could be attributed to the enhanced persistence of glyphosate due to the formation of glyphosate-Ca and $-\mathrm{Mg}$ complexes when hardness is present in water. Similarly, slower degradation rates were observed with Roundup® compared to that of with high purity glyphosate, both in the absence and presence of hardness. The presence of the major adjuvant surfactant [polyethoxylatedtallowamine, (POEA)], which is introduced as an inert ingredient during Roundup ${ }^{\circledR}$ production seems to have enhanced the persistence of glyphosate in water thus causing retardation of Glyphosate degradation by the photocatalysis process. In conclusion, photocatalysis is an effective and efficient technique that could be used to degrade glyphosate in potable water of CKDu prevalent areas in spite of the possible antagonistic effects observed on Glyphosate degradation due to the presence of hardness and/or surfactants.
\end{abstract}

Keywords: CKDu, Glyphosate, Photocatalysis

Proceedings of the $22^{\text {nd }}$ International Forestry and Environment Symposium 2017 of the Department of Forestry and Environmental Science, University of Sri Jayewardenepura, Sri Lanka 